\title{
A contribuição do estoicismo no enfrentamento das angústias existenciais no mundo contemporâneo
}

\author{
The contribution of stoicism in the facing of existential angeries in the \\ contemporary world
}

Rafael Silva Verdival dos Santos ${ }^{1}$

\begin{abstract}
Resumo
Considerando a importância do estoicismo para a Filosofia Ocidental, o presente artigo se propõe a analisar como o pensamento ético estoico pode contribuir para o enfrentamento das angústias existenciais humanas e para a busca do viver bem no contexto de mundo do século XXI. O presente estudo se desenvolve através da análise de obras referenciais da filosofia estoica, bem como artigos científicos publicados em periódicos renomados. Para tanto, em um primeiro momento, realiza um breve apanhado histórico acerca do estoicismo, com o objetivo de viabilizar a compreensão do seu contexto de surgimento, desenvolvimento e principais características. Em seguida, o presente trabalho aborda conceitos específicos da ética estoica clássica, buscando perceber a conotação prática do pensamento em estudo. Por fim, analisa como a filosofia estoica contribui para o enfrentamento da angústia existencial humana e para a busca do viver bem no mundo contemporâneo.

Palavras-chave: Estoicismo. Ética. Contemporaneidade.
\end{abstract}

\begin{abstract}
Considering that the importance of stoicism for Western Philosophy, this article aims to analyze how Stoic ethical thinking can contribute to coping with human existential anxieties and the search for living well in the context of the 21st century world. The present study is developed through the analysis of reference works of Stoic philosophy, as well as scientific articles published in renowned journals. Therefore, at first, it made a brief historical overview about stoicism, with the objective of enabling the understanding of its context of emergence, development and main characteristics. Then, the present work addressed specific concepts of classic stoic ethics, seeking to understand the practical connotation of the thought under study. Finally, he analyzed how Stoic philosophy contributes to the

\footnotetext{
${ }^{1}$ Mestrando em Direito pela Universidade Católica do Salvador (UcSal). Pós-Graduado em Filosofia e Autoconhecimento: uso pessoal e profissional pela Pontifícia Universidade Católica do Rio Grande do Sul. Pesquisador do Grupo JUSBIOMED - Direito, Bioética e Medicina.

E-mail: rafaelverdival@gmail.com. ORCID: https://orcid.org/oooo-ooo1-8393-5618.
} 
confrontation of human existential anguish and to the search for living well in the contemporary world.

Keywords: Stoicism. Ethics. Contemporary.

\section{Introdução}

O estoicismo é uma das escolas filosóficas clássicas mais importantes de todos os tempos. Concebendo a natureza como um cosmo harmonioso e equilibrado, os estoicos se baseiam na racionalidade como forma de adequar o comportamento às leis divinas e naturais comuns a todos os indivíduos. $\mathrm{O}$ estoicismo ensina que a razão deve se sobrepor às paixões na busca pela felicidade. Sendo assim, para ser feliz, é preciso agir com resiliência ante os acontecimentos da vida, já que tudo faz parte da harmonia do cosmo e aos indivíduos cabe a adequação à justa medida.

Assim sendo, o presente artigo pretende enfrentar o seguinte problema: quais são os reflexos do pensamento ético estoico no contexto do século XXI? Considerando, então, os ensinamentos do estoicismo, este trabalho tem como objetivo geral refletir de que maneira a filosofia estoica pode auxiliar o homem contemporâneo no enfrentamento das angústias existenciais e na busca pela felicidade. Para tanto, tem os seguintes objetivos específicos: compreender os principais aspectos da escola estoica; analisar a ética segundo a ótica do estoicismo; refletir sobre a aplicabilidade de algumas ideias estoicas no âmbito da contemporaneidade. Nesta senda, em um primeiro momento, aborda de forma introdutória o desenvolvimento da filosofia estoica, desde o seu surgimento com Zenão de Cítio, em Atenas, até sua incorporação pela doutrina cristã no período da Antiguidade Tardia. Neste desenvolvimento, trata também da construção do pensamento estoico através da noção de natureza e racionalidade em suas três fases.

Em seguida, o estudo analisa o estoicismo a partir de sua perspectiva ética. Para tanto, aponta a importância do estoicismo romano para a formação da ética, tratando, em seguida, das ideias de virtude e vício pautadas na razão. Tudo isso dentro do contexto de uma natureza equilibrada e do justo natural.

Por fim, realiza reflexão acerca de como o estoicismo se mostra instrumento apto ao enfrentamento de angústias existenciais humanas, contribuindo com a busca do bem-viver. Com esta finalidade, destaca a importância da racionalidade, 
da autocompreensão do ser perante a natureza e do hábito filosófico como forma de construção do bem-viver.

\section{$2 \mathrm{O}$ desenvolvimento da filosofia estoica}

O estoicismo é uma escola do pensamento filosófico helenístico fundada por Zenão de Cítio, em Atenas, no início do século III a. C. No berço da filosofia clássica, Zenão (nascido na ilha de Chipre) se muda para Atenas e lá se torna discípulo dos cínicos. Com base na influência desse pensamento, funda a escola estoica (VERGES, 1982, p. 59).

A denominação "estoicismo", inclusive, origina-se do termo grego "stoa poikilé”, que designa o local de reuniões no qual os discípulos de Zenão se encontravam: um pórtico do espaço público para reuniões políticas em Atenas (MARCONDES, 2007, p. 91). Sua doutrina é frequentemente representada pela imagem de uma árvore, na qual o caule simboliza a sua parte física, os galhos a lógica e as folhas a ética ou a moral (MOURA, p. 111).

A filosofia estoica está vinculada à relação entre a natureza e as leis. Os estoicos acreditam que a natureza determina que as pessoas são e como agem Por isso, estudar o estoicismo envolve a necessidade da sua associação com reflexões sobre o cosmo, a lei, as formas e suas relações. A fundamentação do estoicismo está relacionada à idealização de que o princípio constitutivo e a conduta dos seres humanos são baseadas em uma lei divina e natural, comum a todos eles (CÂMARA, 2014, p. 5-6).

É justamente nessa vinculação que se busca os fundamentos para a boa lei. Nesse sentido, os estoicos concebem o cosmos através da harmonização de elementos contraditórios. Essa harmonização - relacionada à ideia de equilíbrio -, se baseia na justa medida que se verifica na natureza.

É notória a relevância do tema "natureza" para o estoicismo. Os elementos naturais são perfeitos e equilibrados, dotados de elemento divino em sua ordenação e constituição. Assim sendo, o indivíduo se insere dentro desse cosmo - que é a natureza estoica equilibrada. Dessa forma, faz-se necessário buscar o equilíbrio natural tanto na vida política quanto na pessoal (GAZOLLA, 1999, p. 41).

Nesse contexto, da ideia de natureza decorre o conceito de razão suprema. Em verdade, essa razão suprema, segundo o estoicismo, seria a própria natureza - 
que é causa e determinação de todas as coisas. Nota-se, segundo Verges (1982, p. 59), que a harmonia que emana do universo é expressão dessa racionalidade inerente à natureza. Em outras palavras, razão e natureza se conectam e formam o fundamento do pensamento estoico. Assim sendo, todo o cosmo estoico é equilibrado, assim como tudo que o compõe deve ser. Logo, o mal existe em função do bem e o homem deve encontrar seu papel nessa harmonia.

Em meio a isso, para os estoicos, a felicidade é um ato de vontade. $\mathrm{O}$ indivíduo alcança a felicidade quando vive de acordo com a natureza, de forma racional, aceitando racionalmente as coisas como elas são - já que o cosmo é perfeito. Todo aquele que controla suas paixões se harmoniza com o cosmo, já que a importância dada às coisas não é nada além de concepções e juízo oriundos da paixão e não da razão (VERGES, 1982, p. 60-61).

A característica mais importante do estoicismo, em sua visão ética pautada na indiferença, é a ataraxia. Essa indiferença deve ser compreendida como prática, superando a mera reflexão intelectual. Se o cosmo é harmônico e equilibrado, a virtude está em viver de acordo seu desígnio. Nesta senda, elementos humanos como saúde, amizades, inimizades ou doenças não devem ser almejados ou rejeitados, pois isso vai de encontro com desenrolar natural do cosmo.

O que é bom ou mau, por sua vez, decorre de elementos incondicionais. Por exemplo, ter uma inimizade depende da ação dos indivíduos, logo, a existência ou não de um inimigo não causa tristeza ou felicidade. A atitude virtuosa consiste na aceitação de causas externas que não dependem do querer. Zenão aponta que para se atingir a felicidade é necessário tal aceitação, que coaduna com a vontade de fazer o bem, afastando-se de direcionar as ações a um fim externo. O modelo de filosofia proposta por Zenão, entretanto, não encerra a completude do pensamento estoico. Em verdade, o estoicismo pode ser dividido em três fases, situadas em períodos específicos no tempo e tendo pensadores diferentes como figuras centrais.

A primeira fase se dá justamente com Zenão (333/332-262 a. C.), em Atenas (CASTRO DE LIMA, 2006, p. 36). O do fundador do estoicismo defende, através de seus ensinamentos, princípios igualitários e explicita, pela primeira vez, a necessidade de a vida seguir a natureza. Além de Zenão, destacam-se nesta fase Cleantes de Assos (331-232 a. C) - defensor do materialismo que concebe a alma como matéria -; e Císipo de Solos (281-208 a. C), responsável pela sistematização dos pensamentos de Zenão e pela defesa dessa filosofia perante as investidas dos 
discípulos de Platão. Ressaltam-se, ainda, os esforços de Císipo em combater falácias e estudar proposições.

Já a segunda fase do estoicismo é marcada pelo contato do pensamento estoico com Roma (CÂMARA, 2014, p. 6)). O início desse período se dá com Diógenes da Babilônia (230 a. C - 150/140 a. C) - e sua chegada em território romano - e Panécio de Rodes (185 a. C - 110/109 a. C), com a retomada de alguns temas platônicos. Outro pensador marcante deste segundo período é Posidônio de Apameia (135 a. C - 51 a. C). Posidônio se aproxima do pensamento platônico, principalmente no que tange à continuidade da alma. Sobre essa relação, explica Russell:

Panécio dissera, como a maioria dos estoicos, que a alma perece junto do corpo. Posidônio, ao contrário, afirma que sua existência tem continuidade no ar, onde permanece intacta, na maioria dos casos, até a próxima conflagração mundial. Não há inferno, mas os iníquos não têm a mesma sorte dos bons, pois o pecado torna os vapores de sua alma lodosos e a impedem de elevar-se até o local a que a alma boa se eleva (RUSSELL, 2015, p.321).

Por fim, a terceira e última fase do estoicismo é aquela que mais fontes textuais fornece, permitindo, assim, melhor compreensão acerca da filosofia estoica (CASTRO DE LIMA, 2006, p. 44). Esse período tem singular relevância do ponto de vista histórico, muito por conta da relação que os pensadores da época tiveram com Roma, quais sejam: Sêneca, Epicteto e Marco Aurélio (RUSSELL, 2015, p. 321). Vale destacar, aqui, as diferentes posições sociais ocupadas por cada um destes homens, sendo, respectivamente, um ministro, um escravo e um imperador.

O nome que inicia este período é Sêneca (4 a. C. -65 d. C.), considerado o principal pensador romano da época. Sêneca enfatiza em seus textos a falsidade existente na resposta emocional aos fatos do dia a dia. Este pensador compreende a mente como uma unidade racional, motivo pelo qual essas respostas, pautadas na emoção ao invés da razão, são falhas no raciocínio. Ainda, de acordo com Sêneca, quando o indivíduo assimila os valores estoicos e passa a viver conforme a virtude e a natureza, passa a não mais necessitar de instrução parada cada situação experimentada. Nesse sentido:

Quando conseguirmos que o homem, instruído nestes princípios, tenha uma clara noção da condição humana, quando tiver entendido que não é feliz a vida que obedece ao prazer mas sim a que obedece à natureza, quando tiver passado a abraçar, como único bem próprio do homem, a virtude e a evitar como único mal o vício, quando tiver percebido que tudo 
o mais - riquezas, honras, saúde, força, poder - ocupa uma posição intermédia, sem ser, em si mesmo, nem um bem nem um mal, então ele não precisará de conselheiro para em cada situação, lhe dizer: "deves andar deste modo, deves jantar daquele; esta é a actuação correcta de um homem, de uma mulher, de um casado ou de um solteiro" (SÊNECA, 2004, p. 481-482)

Outro nome marcante da terceira fase do estoicismo é o escravo liberto Epicteto (55-135). Reza a lenda que a liberdade de Epicteto se dá em virtude de sua resistência apática perante as injúrias físicas que lhe são infligidas por seu senhor. Sua obra, compilada por um de seus discípulos, é utilizada até hoje como guia para adversidades cotidianas. É o conhecido autor da expressão Encheiridion, que significa "pronto à mão" ou "manual"(STOCKDALE, p. 102).

Demonstrando certa diversidade, a filosofia estoica abrange pensadores de diferentes estamentos sociais. Se Epicteto é um mero escravo, outro grande nome do estoicismo é o homem mais poderoso de seu tempo. Trata-se do imperador romano Marco Aurélio (121-180). Um dos poucos reis-filósofos conhecidos na história, escreve diários de aperfeiçoamento pessoal que hoje, compilados sob o título de Meditações (MARCO AURÉLIO, 2001), consistem em um dos textos mais lidos da tradição filosófica.

Não obstante as diferentes características que marcam as três fases do desenvolvimento do estoicismo, é notório o esforço de tal escola de pensamento em tematizar a felicidade enquanto problema filosófico. Ressaltamos que o que todos os estoicos tem em comum é a percepção de que a felicidade não é alcançada através de adequações aos acontecimentos externos. A felicidade, em verdade, remete à aceitação das determinações da natureza (cosmo), que é harmonioso e equilibrado. Ainda, para ser feliz, é imprescindível acolher o que é incondicionalmente bom.

$\mathrm{O}$ estoicismo é marcado pelo equilíbrio emocional de seus praticantes. A felicidade não tem a ver com aspectos exteriores, nem com a repressão ou reação à acontecimentos. Trata-se, de fato, de autocontrole e resiliência perante aos acontecimentos do cosmo, vez que tudo faz parte de uma ordem natural perfeita.

\section{Análise da ética estoica clássica}

A escola estoica constrói bases atemporais sólidas. Até hoje os pensamentos do estoicismo são de grande relevância àqueles que buscam alguma resiliência ante aos problemas da vida hodierna. Mas, antes de nos aprofundarmos nas nuances 
contemporâneas do estoicismo na vida das pessoas, é fundamental compreender como se configura a ética estoica. Para tanto, faz-se necessária uma reflexão introdutória acerca dessa ética em seus moldes clássicos.

A filosofia estoica é sistematicamente dividida. Por conta disso, é possível identificar, em diferentes momentos históricos, a priorização e desenvolvimento de determinadas áreas de interesse particular, deixando de lado outras consideradas superadas ou de menor importância. Essa divisão, por sua vez, tem três parte fundamentais: a física, a lógica e a ética - representadas pela metáfora da árvore (MARCONDES, 2007, p. 91). Nessa senda, o aprofundamento da ética estoica é mais facilmente verificável no período do início da Roma Imperial, principalmente através da elaboração de tratados e escritos morais (MOURA, 2012, p. 112).

Inicialmente, destaca-se que a ética estoica tem como característica, de maneira semelhante a toda a doutrina, o fato de que um conceito depende de outro, ou seja, a exclusão de algum aspecto pode dificultar a compreensão do todo. Além disso, o principal conceito da ética estoica é a virtude, fundamentada no hábito natural do animal de se autopreservar e viver segundo a natureza. A partir dela o estoico guia sua conduta ética e moral, perseguindo o ideal do Sábio. (MOURA, 2012, p. 113). Nesse sentido, conforme destaca Laércio, “o fim é viver conforme à natureza, quer dizer, viver segundo a virtude, de vez que a natureza nos conduz a ela” (LAÉRCIO, 1949, p. 62).

Contudo, o homem possui uma característica natural que o difere do animal e que lhe permite seguir a natureza de maneira mais perfeita: a razão. É esse atributo que o conduz a viver de acordo com a ordem natural do universo. Quando o ser humano segue a razão ele age naturalmente e se torna virtuoso, consequentemente alcança a felicidade. O vício, por sua vez, se fundamenta na ignorância. Enquanto a razão permite que o ser humano entenda as coisas, caracterizando a virtude, o vício é fruto da má compreensão e leva o homem à falsidade, impossibilitando-o de agir em concordância com a ordem natural, resultando, assim, na tristeza. Portanto, o virtuoso é aquele que segue a razão, em conformação a natureza, e o vicioso é aquele que se encontra na ignorância e na falsidade, suscetível às paixões (MOURA, 2012, p. 114).

Se a virtude está relacionada à racionalidade, é fácil perceber que, para a ética estoica, as paixões são perversões mentais causadoras dos fracassos humanos. Desta maneira, o estoicismo entende que as paixões são provocadas por 


\section{8 | Opinião Filosófica, V. 12, 2021}

movimentos irracionais da alma, movimentos que são contrários à natureza. Assim como a virtude é caracterizada por uma condição humana (razão), o vício também é uma particularidade do ser humano, sendo decorrente das opiniões, falsos juízos.

Para os estoicos, somente a virtude é do bem e somente o vício é do mal. Entre eles existe uma grande quantidade de coisas, como doenças, fama, riqueza, saúde, nomeadas indiferentes e que, portanto, não devem ser valorizadas por não influenciarem na felicidade ou na tristeza do homem. Aqueles que apreciam o indiferente possuem uma compreensão deficiente da ordem natural e não conseguem entender que algo usado tanto para o bem quanto para o mal não pode ser considerado nem do bem e nem do mal (MOURA, 2012, p. 115). Nesse sentido, “as riquezas e a saúde não são mais proveitosas que danosas; logo, nem as riquezas nem a saúde são bens. Mais ainda: aquilo que se pode utilizar bem ou mal, não é bom” (LAÉRCIO, 1949, p. 71).

Nesse contexto, quando se trata da ética estoica, deve-se levar em conta a grande influência que a filosofia romana tem para o estoicismo. Panécio, o filósofo de Rodes, é um dos principais filósofos do estoicismo romano. Conhecido por influênciar a alta sociedade romana, Panécio realiza mudanças no estoicismo clássico, adequando a filosofia estoica ao perfil romano. Revisa teses, busca novas ideias decorrentes dos ensinamentos de Platão e Aristóteles, reinterpreta o conceito de apatia -apatheia, a ideia de indiferença e ausência de perturbações - e desenvolve os conceitos de virtudes práticas, o que permite que a ética, a moral e a política se destaquem perante aos romanos. Baseando-se nas novas ideias apresentadas por Panécio sobre à virtude, Cícero (103 a. C-43 a. c), um dos principais nomes da política e intelectualidade romana no final da República, toma os ensinamentos estoicos e os torna ainda mais familiarizado aos interesses do seu Estado (MOURA, 2012, p. 118).

Conforme ensina Reale, Panécio valoriza a vida prática, trazendo "um vivo sentimento de socialidade e um forte sentimento de Estado" (REALE, 1994, p. 372). Essa perspectiva mais prática trouxe muitos romanos ao ideal estoico, enquanto transformava, simultaneamente, próprio estoicismo. Há um certo enfraquecimento da visão cosmopolita anterior em detrimento da prática. Essa mudança se relaciona com a visão estoica romana, mais voltada aos resultados concretos do bem-viver.

O principal emprego da filosofia estoica, com foco na ética, entre os romanos são os aconselhamentos para aqueles que buscam a sabedoria. Essas orientações 
baseiam-se em determinar as ações apropriadas e estabelecer para as pessoas os caminhos entre obter vantagens preferíveis e agir de maneira virtuosa. O estudo das paixões ainda tem grande enfoque na ética estoica romana e continua sendo tratado como um erro da razão, porém agora consideradas doenças que precisam ser curadas por meio do já supracitado aconselhamento (MOURA, 2012, p. 119).

Com o tempo, a ética estoica passa a ditar a conduta de grande parte dos nobres romanos, que possuem acesso aos estudos filosóficos, e acaba sendo difundida para toda a população. A partir da disseminação do estoicismo e da divulgação de novas doutrinas para a sociedade em geral, surgem os pensadores ecléticos que conjugam os ideais e pressupostos de diversas escolas filosóficas. Nesse contexto, o estoicismo romano perde grande parte da sua concisão, já que a ética passa a ser a prioridade de estudo e os aspectos da doutrina referentes à física e à lógica ficam parcialmente abandonados e os conceitos ficam, consequentemente, sem fundamento (MOURA, p. 120).

A partir de Clemente de Alexandria o pensamento estoico passa a ser absorvido por pensadores cristãos, em parte pela influência do platonismo na doutrina cristã. Ideias estoicas como o papel cósmico da razão e a suficiência da virtude são incorporadas, mesmo com a compreensão platônica envolvida (GILL, 2006, p. 60). Com isso, percebe-se que, desde o seu surgimento, o estoicismo vai se transformando. Essa transformação é progressiva, e esse fator é fundamental para sua sobrevivência e relevância no século XXI.

\section{0 pensamento estoico como instrumento do bem-viver}

O mundo contemporâneo é marcado por dilemas mentais. A velocidade dos acontecimentos, o grande volume de informações e a necessidade de lidar com os múltiplos tentáculos das demandas postas pela sociedade muitas vezes "sugam" toda a energia dos seres humanos. Não é à toa que a o aumento dos níveis de ansiedade pode ser verificado em diversas searas da vida - seja no âmbito acadêmico, profissional, familiar ou pessoal (BRITO, 2011) (GOMES; SILVA; ARAÚJO, 2008) (COSTA; et al., 2019. Diante disto, a filosofia estoica vem reaparece como instrumento de enfrentamento desses dilemas e como ferramenta para construção de uma vida melhor no sentido existencial. 
Conforme ensina Stockdale, os estoicos consideram a dor física pouco importante quando comparada à agonia que os homens bons vivenciam ao falhar, durante a realização de seu dever, perante seus companheiros ou a Deus. $O$ fato de os estoicos buscarem formar homens de sanidade, coragem e boa vontade, fez com que reconhecidas famílias enviassem seus jovens filhos para serem ensinados por estes pensadores sobre o que é a vida boa e como devem agir. Epicteto deixa claro que suas audiências tratam sobre a felicidade e infelicidade, o sucesso e a falha, a escravidão e a liberdade e não sobre proventos e rendimentos ou a paz e a guerra. Para ele, cada um é responsável por seus próprios juízos e o erro de um homem não pode causar o sofrimento de outro (STOCKDALE, 2017, p. 103-104).

Nesse sentido, aduz Epicteto:

É ação de quem não se educou acusar os outros pelas coisas que ele próprio faz erroneamente. De quem começou a se educar, acusar a si próprio. De quem já se educou, não acusar os outros nem a si próprio (EPICTETO, 2012, p. 19).

A responsabilidade do indivíduo pela própria conduta é tão importante para o pensamento de Epicteto que nem mesmo injúrias físicas ou doenças seriam suficientes para inviabilizar a escolha - conforme dispõe:

A doença é entrave para o corpo, mas não para a escolha, se ela não quiser. Claudicar é entrave para as pernas, mas não para a escolha. Diz isso para cada uma das coisas que sucedem contigo, e descobrirás que o entrave é próprio de outra coisa e não teu (EPICTETO, 2012, p. 21).

De acordo com Russell, a moral em Epicteto chega a ser "elevada e sobrenatural", uma vez que, para alcançar a felicidade, faz-se necessário se libertar das paixões e das preocupações, reconhecendo que "todo homem é ator numa peça cujos papéis foram definidos por Deus", sendo "nosso dever atuar com dignidade independentemente de qual seja o papel que nos cabe” (RUSSELL, 2015, p. 326).

A felicidade é tema recorrente na história da humanidade. A procura pela chamada "vida feliz" é um ato empreendido desde sempre por homens e mulheres de todos os tempos e lugares. De filósofos clássicos como Epicteto a funcionários de uma grande empresa paulista de tecnologia. É notório que essa ideia de responsabilidade presente em Epicteto traz poder aos angustiados. A prática da virtude é comum a todos. E essa prática, pautada na razão, tem papel fundamental para o alcance da felicidade. 
Epicteto lembra que apenas a aparência não define um filósofo. É necessário observar como ele age, como são suas relações com os outros e como encara o prazer e fatos desagradáveis. Os filósofos se reconhecem pelos atos. A matéria para um filósofo é a razão e o fim é manter a razão correta. A vida do indivíduo e a razão formam a matéria da arte do bem-viver, caracterizada como o arranjo da alma ou razão como um estado mental interno. A filosofia, então, almeja a arte de viver e o homem se encontra em sua direção quando tem atitudes auto reflexiva diante do cosmos, do conhecimento e de suas escolhas (FONTOURA, 2017, p. 68-69).

$O$ viver bem e o alcance da felicidade são exercícios práticos. Sendo assim, as boas práticas que resultam na materialização da virtude devem ser compreendidas como hábitos a serem consolidados. Dentro da filosofia estoica, destaca-se o pensamento de Epicteto em relação ao hábito de boas práticas:

Todo hábito ou capacidade é mantido e desenvolvido por suas atividades correspondentes: o hábito de caminhar nos faz caminhar melhor, a corrida regular transforma-nos em melhores corredores. O mesmo acontece com nossa alma. Sempre que você se zanga ou fica com raiva, mais aumenta sua zanga e a sua raiva. Você intensifica um hábito e coloca lenha na fogueira [...]. Se você não quer ter um mau gênio, não alimente o hábito [...] (EPICTETO, 2006, p. 86-87).

Diogo Luz discorre bem sobre o hábito como exercício filosófico. Nesse sentido, destaca que, para Epicteto, a disposição habitual é decorrente da repetição de determinadas ações, que geram respostas mais diretas para as próximas situações. A atividade de habituar-se às boas práticas fortalece aquele que segue $o$ caminho filosófico defendido por Epicteto. Para o filósofo, deve-se colocar em prática o que se aprende em filosofia e se habituar a agir como um filósofo e não apenas a falar como um. O hábito e a ação de se habituar estão relacionadas aos aspectos mentais do indivíduo (LUZ, 2018, p. 89-90).

Em relação às situações que levam ao vício, Epicteto aconselha o hábito de voltar-se para si mesmo a fim de confrontá-los e buscar uma direção oposta a ele. A atitude filosófica de contraposição é necessária visto que aquele que não se opõe aos antigos hábitos se tona apenas um intérprete de doutrinas alheias e não um filósofo (LUZ, 2018, p. 91-92).

Para a filosofia epictetiana tudo o que for externo à mente é não-preferível e só pode ser considerado como bem por equívoco. Por isso, o homem deve se habituar a corrigir os desejos por aquilo que não depende dele e a ficar atento às 
situações. A luta com as representações é feita em três estágios: não se deve deixar ser atraído pela representação sem saber do que se trata; não se deve deixar ser dominado por ela; e, enfim, deve-se realizar uma representação correta a fim de extinguir o erro (LUZ, 2018, p. 92-94).

Viver de acordo com as ideias estoicas auxilia o enfrentamento dos problemas do mundo contemporâneo. Lembremos que o estoicismo é uma filosofia que compreende a razão como preterível ante às paixões. Logo, o viver se relaciona com o entendimento racional dos acontecimentos como consequência de um cosmo equilibrado. Dessa compreensão, emana a responsabilidade de agir em conformidade com o cosmo. Embora esse tipo de pensamento possa, inicialmente, parecer conformista, em verdade é libertador. É razoável afirmar que há, em verdade, uma resiliência racional que alivia as angústias.

Os estoicos estão em busca dos bons sentimentos, impulsos racionais, e não da aniquilação dos sentimentos da alma. Em relação à acusação da busca do domínio absoluto das razões pelos estoicos pode-se citar o pensador moderno Spinoza. que no prefácio ao livro V de sua Ética aponta-os como defensores da ideia de que as paixões podem ser controladas e dependem da vontade individual. De acordo com Spinoza, os estoicos defendem a tese de que o homem possui algum poder sobre as paixões por meio da razão, porém esse poder não é absoluto. Como o incumbido por modificar a causa interna é um afeto oriundo da razão, é mais correto declarar que os estoicos pretendem controlar um afeto irracional mediante um afeto racional (MOURA, 2012, p. 124).

Disso tudo, o que se pretende demonstrar é que o estoicismo, no contexto do mundo contemporâneo tem importância ímpar na manutenção da chamada "saúde mental 2". Nesse sentido, inclusive, discorre o filósofo Bertrand Russel, em seu ensaio Stoicism and Mental Health.

De acordo com Russel, a morte é considerada o problema mais difícil e essencial em relação ao estoicismo. Existem três formas de como as pessoas lidam com a morte e com o fato de que um dia todos morrerão: a ignorando e evitando pensar no assunto; discorrendo com frequência sobre a questão a fim de se familiarizar; e acreditando que a morte é a passagem para uma vida nova e melhor

\footnotetext{
${ }^{2}$ Saúde mental é aqui entendida de acordo com a definição proferida pela Organização Mundial de Saúde - OMS : "A saúde é um estado de completo bem-estar físico, mental e social, e não consiste apenas na ausência de doença ou de enfermidade" (ORGANIZAÇÃO MUNDIAL DE SAÚDE, 1946). 
(RUSSELL, 2014, p. 244).

Reflexões acerca da finitude da vida são, de fato, recorrentes no pensamento estoico. Sobre o assunto, Marco Aurélio discorre:

¿Qué es la muerte? Porque si se la mira a ella exclusivamente y se abstraen, por división de su concepto, los fantasmas que la recubren, ya no sugerirá otra cosa sino que es obra de la naturaleza. Y si alguien teme la acción de la naturaleza, es un chiquillo. Pero no sólo es la muerte acción de la naturaleza, sino también acción útil a la naturaleza. Cómo el hombre entra en contacto con Dios y por qué parte de sí mismo, y, en suma, cómo está dispuesta esa pequeña parte del hombre (MARCO AURÉLO, 1977, p. 63$64)$.

De acordo com Marco Aurélio, a morte é apenas um fenômeno ordinário da natureza, razão pela qual não deve ser motivo de temor - afinal, apenas crianças se assustariam com um fenômeno natural. A ideia de que o fim da vida não é algo a ser temido também se mostra presente em Epicuro, que escreve sobre o assunto em Carta a Meneceu:

Então, o mais terrível de todos os males, a morte, não significa nada para nós, justamente porque, quando estamos vivos, é a morte que não está presente; ao contrário, quando a morte está presente, nós é que não estamos. A morte, portanto, não é nada, nem para os vivos, nem para os mortos, já que para aqueles ela não existe, ao passo que estes não estão mais aqui. E, no entanto, a maioria das pessoas ora foge da morte como se fosse o maior dos males, ora a deseja como descanso dos males da vida (EPICURO, 2002, p. 29).

Embora a abordagem estoica sobre a morte aponte para a necessidade se encarar tal fenômeno com naturalidade, pensar no final da vida levanta temores. Não obstante, a ausência de reflexão sobre episódios que envolvam desgaste emocional, como a morte, é frustrante e pode acarretar em desequilíbrio. Crer que a morte é a passagem para uma vida melhor - ou que ela nunca está presente de fato - não impede que os homens sintam medo da mesma, já que a fé religiosa se encontra apenas no local do pensamento consciente e não afeta, em grande parte das pessoas, os comportamentos como um todo, incluindo os mecanismos inconscientes (RUSSELL, 2014, p. 244-245).

Refletindo sobre possíveis formas de se superar o medo da morte, Russell sugere a utilização um método capaz de afetar o comportamento do indivíduo de forma geral - não apenas o seu pensamento consciente. Utilizando o exemplo dos jovens, discorre: 


\begin{abstract}
O que então deveria ser feito com os jovens para acostumá-los a um mundo no qual a morte existe? Nós temos que atingir três objetivos, que são muito difíceis de combinar. (1) Não devemos dar-lhes a impressão que a morte é um assunto do qual não queremos falar ou encorajá-los a pensar nela. Se deixarmos transparecer isso, eles concluirão que existe um mistério interessante na morte e pensarão ainda mais no assunto. Nesse ponto, a educação familiar moderna a respeito do sexo é aplicável. (2) Nós devemos, todavia, agir para preveni-los, se pudermos, de pensar muito ou frequentemente sobre a morte; o mesmo tipo de objeção é feito contra a pornografia, por diminuir a eficiência, impedir um amplo desenvolvimento e levar a condutas que são insatisfatórias para a pessoa mesma e para com os outros.(3) Se quisermos criar uma atitude satisfatória sobre a morte em alguém, não devemos contar unicamente com o pensamento consciente; especialmente porque nenhum bem é feito por crenças que pretendem mostrar que a morte é menos terrível do que ela seria, quando (como ocorre normalmente) tais crenças não penetram abaixo do nível da consciência. (RUSSELL, 2014, p. 246).
\end{abstract}

Para que tais objetivos sejam alcançados é necessário agir conforme a experiência da criança ou do jovem. Durante o tempo em que a morte for algo abstrato e impessoal, ou seja, enquanto a criança ou o jovem não viver a morte de alguém próximo, deve-se tratá-la de maneira imparcial e evitar que criem sensação de mistério a respeito da mesma. Em contrapartida, quando a criança passa pela morte de uma pessoa próxima a ela é indicado que não se evite o assunto e nem se minimize (RUSSELL, 2014, p. 246-247).

Em crianças, afeições podem ser criadas, resultantes do medo, e lhes dando sentimento de segurança. Para a fase da infância, afeições como essa não são positivas e é em um ambiente amigável, em que ela se sinta feliz, em que a dor pela perda será superada. Já durante a adolescência é preciso que se tenha atitudes mais positivas relacionadas a morte para influenciar positivamente na fase adulta. $\mathrm{O}$ adulto deve pensar pouco sobre a morte e de maneira estoica, intencional e calma, sem desprezá-la e sentindo orgulho de sua superação. O homem deve entender que existem uma variedade de interesses e atividades importantes pelas quais se vive e, para isso, o jovem, na sua adolescência, deve ser estimulado a construir sua vida e carreira voltadas a tais importâncias (RUSSELL, 2014, p. 247).

Existem duas maneiras de lidar com o infortúnio: tentar evitá-lo ou enfrentálo. A primeira pode ser considerada positiva se usada sem covardia, enquanto a segunda será necessária em algum momento. Essa é a conduta do estoicismo. Para um educador, semear o estoicismo nos jovens é difícil a partir do momento em que é aberta uma válvula de escape para o sadismo. A disciplina deve estar voltada ao desenvolvimento do caráter ou da inteligência e é preciso que a criança ou o 
adolescente estejam dispostos a fazer esforços para atingir algo difícil (RUSSELL, 2014, p. 250).

A matéria prima é resultado da prática, que por sua vez se resulta da junção entre a teoria e o exercício e entre a razão e a prática. O resultado final acompanha aquele que domina o processo e a avaliação sobre o que deve ou não ser feito é de total responsabilidade de quem executa. Dessa forma, como para Epicteto a filosofia de vida é baseada na responsabilidade sobre o processo e o resultado, a arte performativa é um paradigma para a arte do bem-viver (FONTOURA, 2017, p. 7879).

Para que os atos em direção à sabedoria sejam efetivados, o filósofo deve considerar o que for externo a ele como indiferentes. As ações que não dependem totalmente do indivíduo, seja no processo ou no resultado, são chamadas ações apropriadas e respondem a tendências naturais da vida humana. Dessa forma, o que conta não é o resultado das ações e sim a intenção, fazendo com que a arte estocástica seja um bom paradigma das ações apropriadas (FONTOURA, 2017, p. 80-81).

Assim sendo, é possível perceber que a contribuição estoica para o enfrentamento dos dilemas humanos do século XXI reside no estímulo à prática da resiliência. Essa resiliência, por sua vez, consiste na tomada de decisão pautada na prevalência da razão sobre as paixões. É compreender que tudo que acontece é reflexo do movimento de um cosmo que é harmonioso e equilibrado. Esse entendimento, por sua vez, não implica conformismo, ou até mesmo apatia. Em verdade, trata-se de encontrar um lugar de paz que permite enfrentar os problemas do dia a dia com leveza e objetividade. É dar-se conta de que tudo faz parte da natureza e assim buscar a harmonização com o mundo equilibrado.

\section{Conclusão}

Considerando que o exposto, o presente artigo analisa quais são os reflexos e possíveis contribuições do pensamento ético estoico no contexto do mundo contemporâneo. Para tanto, em um primeiro momento, realiza um breve apanhado histórico acerca do estoicismo, com o objetivo de explicitar elementos acerca de seu contexto de surgimento e desenvolvimento, bem como suas principais características. Em seguida, expõe os conceitos específicos da ética estoica clássica, 
buscando perceber a conotação prática do pensamento em estudo. Por fim, investiga de que forma a filosofia estoica contribui para o enfrentamento da angústia existencial humana e para a busca do viver bem no mundo contemporâneo.

Deste modo, o presente estudo infere que o estoicismo não é uma filosofia de mero conformismo. Em verdade, por meio da autocompreensão de seu lugar na natureza, do uso da razão e do exercício filosófico como hábito, é possível ao indivíduo alcançar uma resiliência que lhe permite lidar com problemas do dia-adia, de caráter existencial ou não, com maior leveza, vez que se entende que existem situações que fogem do controle, já que essas situações são manifestações de uma natureza que é equilibrada e perfeita. Ao ser humano, então, cabe, através da razão, adequar-se a esse justo natural - e consequentemente, viver melhor.

\section{Referências}

BRITO, Isabel. Ansiedade e depressão na adolescência. Revista Portuguesa de Medicina Geral e Familiar, v. 27, n.2, 2011. Disponível em: < https://rpmgf.pt/ojs/index.php/rpmgf/article/view/10842 > Acesso em 15 de junho de 2021.

CÂMARA, Uipirangi Franklin da Silva. A porta e o jardim: uma introdução ao epicurismo e estoicismo da Grécia pós-socrática. Revista Eletrônica do Curso de Pedagogia das Faculdades OPET, p. 1-11, Junho de 2014. Disponível em: < http://www.opet.com.br/faculdade/revista-pedagogia/pdf/n7/ARTIGO-UIPIRANGI.pdf $>$ Acesso em 31 de julho de 2020.

CASTRO DE LIMA, Abili Lázaro. Cosmopolitismo e globalização: efeitos na seara político-jurídica contemporânea. Revista Eletrônica do CEJUR, [S.l.], dez. 2006. ISSN 1981-8386. Disponível em: < https://revistas.ufpr.br/cejur/article/view/14832 >. Acesso em 31 de julho de 2020.

COSTA, Aline; NOBRE, Camila; GOMES, Giovana, et al. Sentimentos gerados na família pela internação hospitalar da criança. Journal of Nursing and Health, v. 9, n.2, 2019. $\quad$ Disponível em: < https://periodicos.ufpel.edu.br/ojs2/index.php/enfermagem/article/view/14012 > Acesso em 15 de junho de 2021.

EPICTETO. A arte de viver bem: uma nova interpretação de Sharon Lebell. Rio de Janeiro: Sextante, 2006.

EPICTETO. Encheiridion de Epicteto. Edição Bilíngue. Tradução do texto grego e notas Aldo Dinucci; Alfredo Julien. Textos e notas de Aldo Dinucci; Alfredo Julien. São Cristóvão. Universidade Federal de Sergipe, 2012. 
EPICURO. Carta sobre a felicidade: a Meneceu; tradução de Álvaro Lorencini e Enzo Del Carratore. São Paulo: Editora UNESP, 2002.

FONTOURA, Fernando. A arte do bem-viver e seu modelo estrutural segundo a filosofia de Epicteto. Prometeus, ano 10, número 22, p. 65-84, janeiro-abril/2017.

GAZOLLA, R.O ofício do filósofo estóico: o duplo registro do discurso da Stoa. São Paulo: Loyola, 1999.

GILL, Christopher. A escola no período imperial romano. In: INWOOD, Brad (org). Os Estóicos. São Paulo: Odysseus Editora, 2006.

GOMES, Vanessa; SILVA, Maria; ARAÚJO, Eutália. Efeitos gradativos do toque terapêutico na redução da ansiedade de estudantes universitários. Revista Brasileira de Enfermagem, v. 61, n. 6, dez. 2008. Disponível em < https://www.scielo.br/j/reben/a/hrQ7vjcFtRkrHR985cg.5tzJ/?lang=pt > Acesso em 16 de junho de 2021.

LUZ, Diogo da. O hábito como exercício filosófico em Epicteto. Prometeus, ano 11, número 27, maio-agosto/2018, p. 82-96.

MARCO AURÉLIO. Meditaciones. Madrid: Editorial Gredos, 1977.

MARCONDES, Danilo. Iniciação à história da filosofia: dos pré-socráticos a Witgenstein. $2^{\mathrm{a}}$ ed. Rio de Janeiro: Zahar, 2007.

MOURA, Drayfine Teixeira. A ética dos estoicos antigos e o estereótipo estoico na modernidade. Cadernos Espinosanos, n. 26, p. 111-128, 15 jun. 2012.

ORGANIZAÇÃO MUNDIAL DA SAÚDE. Constituição da Organização Mundial da Saúde (OMS/WHO). $1946 . \quad$ Disponível em $<$ http://www.direitoshumanos.usp.br/index.php/OMS-Organiza\%C3\%A7\%C3\%A30-

Mundial-da-Sa\%C3\%BAde/constituicao-da-organizacao-mundial-da-saudeomswho.html> Acesso em 15 de junho de 2021.

REALE, Giovanni. História da filosofia antiga. São Paulo: Loyola, 1994.

RUSSELL, Bertrand. Estoicismo e Saúde Mental. Prometeus, ano 7, número 15, Janeiro-Junho/2014, p. 243-250.

RUSSELL, Bertrand. História da filosofia ocidental - Livro 1: A filosofia antiga. Tradução: Hugo Langone. $1^{\text {a }}$ ed. Rio de Janeiro: Nova Fronteira, 2015.

SÊNECA, Lúcio Aneu. Cartas a Lucílio. $2^{\mathrm{a}}$ edição. Lisboa: Fundação Calouste Gulbenkian, 2004.

STOCKDALE, James Bond. Tradução: Stockdale sobre o estoicismo II: mestre do meu destino - um filósofo estoico numa prisão em Hanói. Prometeus, ano 10, número 22, janeiro-abril/2017, p. 101-116. 
18 | Opinião Filosófica, V. 12, 2021

VERGES, A. História dos filósofos. André Vergez e Denis Huisman. 5 ed. Rio de Janeiro: Freitas Bastos, 1982.

Recebido em: 31/07/2020.

Aprovado em: 01/07/2021.

Publicado em: 05/08/2021. 